\title{
Yield determination in olive hedgerow orchards. II. Analysis of radiation and fruiting profiles
}

\author{
David J. Connor $^{\mathrm{A}, \mathrm{B}}$, Ana Centeno ${ }^{\mathrm{A}}$, and María Gómez-del-Campo ${ }^{\mathrm{A}, \mathrm{C}}$ \\ ADpto. Producción Vegetal: Fitotecnia, AgSystem Research Group, Ciudad Universitaria sn. 28040 Madrid, \\ Universidad Politécnica de Madrid, Spain. \\ ${ }^{B}$ Melbourne School of Land and Environment. The University of Melbourne, Vic. 3010, Australia. \\ ${ }^{\mathrm{C}}$ Corresponding author. Email: maria.gomezdelcampo@upm.es
}

\begin{abstract}
Profiles of fruit density, fruit size, and oil content were measured on 12 occasions in 7 olive orchards in Spain and 2 in Australia. Orchard structure varied widely. Height ranged from 2.0 to $5.5 \mathrm{~m}$, row spacing from 3 to $6 \mathrm{~m}$, and canopy width from 0.7 to $3 \mathrm{~m}$. Most orchards were oriented north-south (N-S) but one in Spain was oriented close to east-west (E-W) $\left(20^{\circ} \mathrm{NE}-\mathrm{SW}\right)$. All orchards in Spain were cv. Arbequina, and in Australia they were cvv. Barnea and Picual. Analyses with a model of interception and transmission that estimated interception by individual sides of hedgerows revealed that fruit size and oil content were strongly related to intercepted radiation during the month before harvest across all orchards. Relationships were also evident between fruit density and interception but varied among orchards and years, indicating the importance of other environmental and probably physiological effects. In N-S orchards of cv. Arbequina, average fruit size and oil content increased linearly from $0.40 \mathrm{~g}$ (dry weight) to $0.72 \mathrm{~g}$, and from 36 to $49 \%$ (of dry weight), as daily intercepted PAR increased from 6 to $25 \mathrm{~mol} / \mathrm{m}^{2}$ (15-60\% of horizontally incident radiation). The general principles of response extended to E-W orchards. There, it was shown that generally large fruit with high oil content on $\mathrm{S}$ sides was consistent with the plateau responses to radiation evident in the more extensive $\mathrm{N}-\mathrm{S}$ data. On the $\mathrm{N}$ side, however, and accounting for transmission through the hedgerow, both fruit size and oil content were greater than in positions intercepting equivalent radiation in N-S orchards. Examples are provided of the utility of responses of fruit density, size, and oil content in establishing combinations of row height, row width, and row distance to improve or maintain productivity in some of the
\end{abstract} orchards included in the study.

Additional keywords: Olea europaea L., radiation model, fruit number, oil content, fruit size.

\section{Introduction}

The requirement for optimum orchard design, i.e. high, continuing, and manageable yield, has not changed since elaborated by Jackson (1980) when he reviewed a then considerable body of literature recording observations on a variety of orchard crops and planting systems. The objective, he advised, is to maximise interception of radiation by canopies while maintaining an optimum distribution of irradiance on the constituent foliage for maximum fruit yield and quality. Calculations with geometrical models for opaque hedgerows of various shapes revealed the importance of height-row spacing ratios in illumination profiles on hedgerow walls and the contrast between opposing walls of east-west hedgerows (Cain 1972; Jackson and Palmer 1972). Subsequently, Palmer and Jackson (1977) added the exponential extinction profile (EEP) of gap frequency to relate transmission through porous hedgerows to observations on leaf area density, leaf angles, and distribution. The objective was a better calculation of interception encouraged by good correlations that were readily established between interception and productivity.

Interest in canopy structure and productivity of hedgerow orchards has intensified in the last decade and further models have been proposed. One theme has been adaptation of models of opaque hedgerows to specific problems. Connor(2006), working with olive, added a procedure to optimise illumination profiles on canopy walls for maximum productivity. Olesen et al. (2007) extended the range of analysis to include hedgerow shapes appropriate to macadamia plantations in the subtropics. Their work, and those of Friday and Fownes (2001) and Oyarzun et al. (2007), included gap analysis for improved estimation of interception and continued focus on hedgerow productivity. A parallel theme was study of radiation environment within hedgerows. Various models have demonstrated the utility of EEP to estimate light distribution (Annandale et al. 2004), photosynthesis (Gijzen and Goudriaan 1989), and also transpiration (Cohen and Fuchs 1987; Cohen et al. 1987) in hedgerows. Annandale et al. (2004) concluded that their model of radiation penetration offered not just accurate estimates of interception for yield prediction, but could also be useful for research into fruit colouring and quality. That work has not proceeded. Progress in those aspects of orchard performance and design requires extensive measurement in the field to define responses of yield-forming processes of individual crops to irradiance. Models of incidence and transmission of solar 
radiation are relatively easily established and validated because the problem is geometrical and deterministic. By contrast, plant responses in the field are variable and potentially responsive to factors outside the experimental design.

This study seeks to explain observed profiles of yield components (fruit density, size, and oil content) in relation to radiation intercepted by individual sides of olive hedgerows of varied structure. Detailed information on structure and profiles of yield components in 2 olive orchards, oriented N-S and E-W, respectively, were obtained over a 2-year period in a companion study (Gómez-del-Campo et al. 2009, this issue). In this paper we combine that and harvest data from other $\mathrm{N}-\mathrm{S}$ orchards with output from a canopy illumination and transmission model to investigate yield relationships with profiles of radiation intercepted by individual sides of $\mathrm{N}-\mathrm{S}$ and $\mathrm{E}-\mathrm{W}$ hedgerows to further develop a system to evaluate optimum design and management of olive hedgerow orchards.

\section{Materials and methods}

\section{Profiles of incident irradiance}

The model of hedgerow illumination developed by Connor (2006) calculates profiles of photosynthetically active radiation (PAR) incident on faces of solid hedgerows according to latitude of site, row orientation, row height, row spacing, canopy width at base, and canopy slope. It treats direct (beam) and diffuse (sky) radiation separately and adds 5\% reflection, as derived from measurements, from adjacent sunlit faces to diffuse sky radiation entering alleys.

A test of the model was made in 2006 at El Carpio del Tajo (Toledo, Spain; $39.9^{\circ} \mathrm{N}, 4.5^{\circ} \mathrm{W}$ ) on clear-sky days in two hedgerow orchards of comparable structure but different orientation. One orchard is oriented NS (Orchard 9, Appendix 1), the other $20^{\circ} \mathrm{NE}-\mathrm{SW}$ (Orchard 11, Appendix 2). They are referred to as $\mathrm{N}-\mathrm{S}$ and $\mathrm{E}-\mathrm{W}$, respectively. The structures are described in detail in Part I (Gómez-del-Campo et al. 2009, this issue) but briefly, rows are spaced at $4 \mathrm{~m}$, canopy width is $c .1 \mathrm{~m}$, and height increased from 2.0 to $2.5 \mathrm{~m}$ during the study period. The model was evaluated by comparing predicted profiles of PAR incident on canopy faces with measurements taken at regular intervals from dawn until noon on 3 clear-sky days close to the winter (day of year, doy 12) and summer (doy 177) solstices and the autumn equinox (doy 253), respectively. Measurements were made with 2 hand-held linear $(0.8 \mathrm{~m})$ ceptometers (SF-80 Decagon Devices, Pullman, WA, USA) at 4 levels $(0.5,1.0,1.5$ and $2.0 \mathrm{~m}$ height $)$ at 8 positions in each orchard. Regular measurements of incident PAR, made with the same instruments, were used to calibrate model predictions of horizontally incident PAR (beam plus diffuse components) at the site.

\section{Extending the model for interception by porous hedgerows}

The model was extended to include transmission of beam radiation through hedgerows towards shaded faces with EEP in order to estimate interception separately by the two sides (halves). The geometry is clearly complex because sunflecks are diffused by leaf movement and by penumbral effects. As a first approximation, row porosity $(\rho)$ is defined here as the proportion of horizontal gap that can be estimated visually for various canopy heights, from point quadrats (Smart 1982), or from photographs (Gómez-del-Campo et al. 2009). An extinction coefficient can be calculated from hedgerow width (w) for unit path length as $[-\ln (\rho) / w]$. The transmittance of direct solar radiation can then be estimated for all other path lengths $[\mathrm{w} /(\cos \theta \cos \Delta \phi)]$ through the hedgerow, determined by combinations of solar elevation $(\theta)$ and azimuth relative to row direction $(\Delta \phi)$. This requires that distributions of leaf angles and orientations that determine horizontal gap are also appropriate to all other directions of passage. If transmittance for a horizontal beam normal to a hedgerow (row porosity) is $\rho$, then as path length increases, gap decreases according to $\exp [\ln (\rho) /(\cos \theta \cos \Delta \phi)]$. Detailed observations and modelling of radiation transmission and interception by olive trees by Mariscal et al. (2000) support application of this method. Transmission was calculated to midlines of hedgerows to estimate PAR entering shaded sides and at full distance to estimate PAR transmitted through hedgerows. Interception by sunlit sides is thus diffuse (sky) plus direct beam incident on sunlit faces less transmission through to hedgerow midline. For shaded sides, it is diffuse sky plus reflected radiation incident on shaded faces plus direct beam entering at hedgerow midline that does not continue through to the shaded alley.

\section{Transmission through hedgerows}

The modified model was used to compare daily interception patterns of PAR in N-S (Orchard 9, Appendix 1) and E-W (Orchard 11, Appendix 2) hedgerow orchards from El Carpio de Tajo, Toledo, Spain, on middle days of successive months from January to June. Comparisons are made for horizontal porosities of 0 (solid), 10, 20, and 30\%.

\section{Yield profiles}

Yield data used for analysis were taken from Gómez-del-Campo et al. (2009) and unpublished studies by the authors. They are summarised in Appendix 1 and 2. Orchards cover a large range of row height $(2.0-5.5 \mathrm{~m})$, row spacing $(3-6 \mathrm{~m})$, hedgerow width $(0.7-3 \mathrm{~m})$ and latitude $\left(34.5^{\circ}-39.9^{\circ}\right)$, with samples from both Hemispheres. Harvest data comprise profiles of average fruit density, fruit dry weight, and oil content ( $\%$ dry weight). Data are presented as means of two sides for N-S hedgerows and separately for $\mathrm{N}$ and $\mathrm{S}$ sides of $\mathrm{E}-\mathrm{W}$ hedgerows. Samples were commonly based on individual trees (sample width $=$ tree spacing), while depths of layers varied $(0.4$ to $1.0 \mathrm{~m})$ between studies as determined by hedgerow height and resources available. In Appendix tables, fruit density is expressed per $\mathrm{m}^{2}$ of hedgerow (one side) to account for variation in sample size.

Daily intercepted radiation is expressed as either $\mathrm{mol} / \mathrm{m}^{2} \mathrm{PAR}$, or $\%$ of daily horizontally incident that is $40.9 \mathrm{~mol} / \mathrm{m}^{2}$ on clear days in mid October for the Northern Hemisphere or March for the Southern Hemisphere.

\section{Simulating effect of canopy structure on productivity}

Yield of hedgerows (g oil $/ \mathrm{m}$ row) is the sum of products of fruit density (/m of hedgerow side), fruit size ( $\mathrm{g}$ dry weight), and fruit oil content ( $\%$ dry weight) for component layers. To make preliminary evaluations of the effect of hedgerow structure on interception and productivity, some variations of two studied orchards (Orchards 7 and 10, Appendix 1) were analysed. For 
this, relationships established between fruit density, size, and oil content and intercepted radiation were combined with simulations of hedgerow interception, as described previously, to account for hedgerow porosity. Linear regression was used to describe the sloping part of those responses.

Three comparisons of fruit and oil production were made based on Orchard 10 (Appendix Table 1). The first evaluated effect of porosity; the second, hedgerow height and width; and the third, porosity and orientation. A fourth comparison concerned hedgerow width and slope for Orchard 7 (Appendix Table 1). In both orchards, canopy depth is row height less $0.5 \mathrm{~m}$ maintained clear at the base to facilitate access of harvesting machinery.

\section{Results}

\section{Validation of canopy model of incident radiation}

Comparisons of predicted and measured PAR incident at 4 heights on canopy faces are presented separately for sunlit $\mathrm{N}-\mathrm{S}$ and E-W hedgerows in Fig. 1. The solar path is highly predictable so strong agreement $\left(R^{2}=0.97\right)$ between observed and predicted irradiance on cosine-corrected sensors facing normally outwards from canopy walls is not surprising. Variation in the data probably relates most to difficulty in holding sensors still to obtain representative measurements on the clear-sky days chosen for measurement. Calibration data reveal distinction between PAR incident on sunlit faces of $\mathrm{N}-\mathrm{S}$ (Fig. $1 a$ ) and E-W (Fig. 1b) orchards. The N-S hedgerow (both faces) recorded highest values of incident radiation in summer (Fig. 1 $a$, doy 177), whereas the E-W hedgerow ( $\mathrm{S}$ face only) recorded highest values in winter (Fig. 1b, doy 12). Autumn (Fig. 1b, doy 253) was a period of higher irradiance on the $\mathrm{S}$ face of the $\mathrm{E}-\mathrm{W}$ than on either face of the N-S hedgerow.

Equal numbers of measurements were also made on shaded faces. These calibrations, although more variable, are strong given the low PAR and absence of marked profiles. A few measurements exceeded $150 \mu \mathrm{mol} / \mathrm{m}^{2}$.s and so are omitted from Fig. 1. As separate calibrations, predicted irradiance $=$ $0.96 \times\left(R^{2}=0.59, n=82\right)$ and $1.07 \times\left(R^{2}=0.51, n=87\right)$, respectively, for NS and EW orchards ( $\times$ is measured irradiance).

Interception by sunlit and shaded sides of hedgerows

Simulated average daily interception of PAR by foliage of individual sides of $\mathrm{N}-\mathrm{S}$ and $\mathrm{E}-\mathrm{W}\left(20^{\circ} \mathrm{NE}-\mathrm{SW}\right)$ hedgerows (Fig. 2) of similar structure (height $2.5 \mathrm{~m}$, free alley width $3.0 \mathrm{~m}$ ) of varying porosity at $39.9^{\circ} \mathrm{N}$ reveals important aspects

Table 1. Simulated yield for variations of horizontal porosity of a N-S oriented cv. Arbequina orchard at Toledo, Spain (Orchard 10, Appendix 1)

The data are for either side with a yield total also presented for the hedgerow

\begin{tabular}{lrrrrr}
\hline & \multicolumn{5}{c}{ Horizontal porosity (\%) } \\
& \multicolumn{1}{c}{0} & \multicolumn{1}{c}{10} & \multicolumn{1}{c}{20} & \multicolumn{1}{c}{30} & \multicolumn{1}{c}{40} \\
\hline Fruit number (/m side) & 1668 & 1711 & 1706 & 1683 & 1601 \\
Mean fruit size (g) & 0.553 & 0.550 & 0.538 & 0.522 & 0.501 \\
Mean oil content (\% DW) & 41.5 & 41.4 & 40.9 & 40.3 & 39.5 \\
Oil production (g/m side) & 375 & 379 & 366 & 346 & 312 \\
Oil production (kg/ha) & 1877 & 1899 & 1832 & 1730 & 1561 \\
\hline
\end{tabular}

relative to interpretation of yield profiles, especially in porous E-W hedgerows.

Hedgerows oriented $\mathrm{N}-\mathrm{S}$ intercept solar radiation symmetrically on either side during the day (Fig. 2a). Interception decreases with porosity but the effect is small because incidence angles of beam radiation are small when irradiance is large. A N-S hedgerow with $20 \%$ horizontal porosity intercepts $99 \%$ PAR incident on canopy faces in winter, decreasing to only $95 \%$ in summer. This contrasts with hedgerows oriented E-W. Dealing first with the $\mathrm{S}$ side the analysis in Fig. $2 b$ reveals greater interception in early spring/ late autumn than occurs in $\mathrm{N}-\mathrm{S}$ orchards. Effect of porosity is much greater than in $\mathrm{N}-\mathrm{S}$ hedgerows during that time because high irradiance coincides with large angles of incidence. In summer, interception by $\mathrm{S}$ sides of $\mathrm{E}-\mathrm{W}$ hedgerows falls below that of either side of $\mathrm{N}-\mathrm{S}$ hedgerows, and impact of porosity is small. The S side of EW hedgerows with $20 \%$ horizontal porosity intercepts just $73 \%$ of incident PAR in winter, increasing to $99 \%$ in summer (Fig. 2b). The $\mathrm{N}$ side of E-W hedgerows is shaded throughout the year except for short periods in the early morning and late evening during

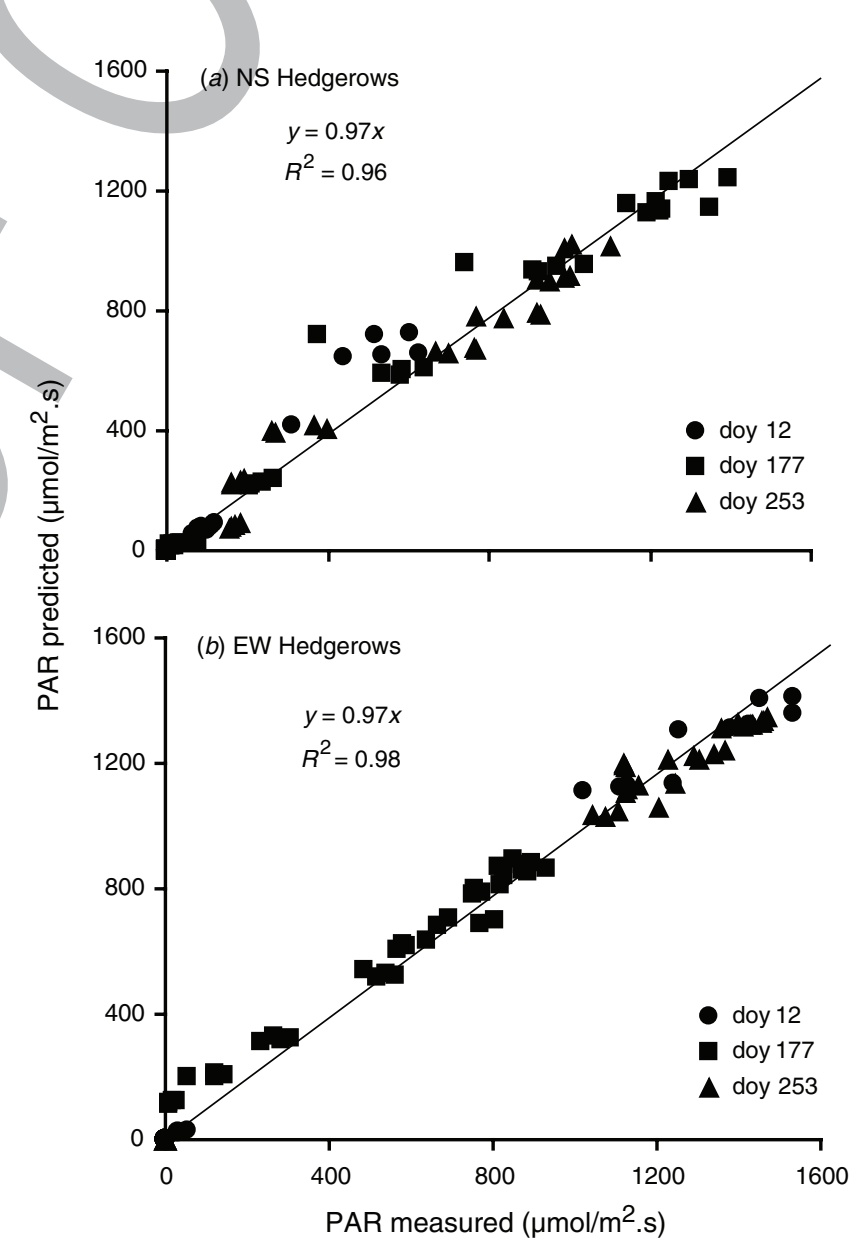

Fig. 1. Predicted and measured PAR incident on the sunlit faces of $(a) \mathrm{N}-\mathrm{S}$ and $(b) \mathrm{E}-\mathrm{W}$ hedgerow orchards on 3 days during the year at El Carpio del Tajo, Spain. The structures of the hedgerows are described in Appendix 1 (Orchard 9) and Appendix 2 (Orchard 11). More detail is available in Gómezdel-Campo et al. (2009), this issue. 
summer months. The consequence is one of small incident PAR. In the case of the $20^{\circ} \mathrm{NE}-\mathrm{SW}$ hedgerows evaluated in Fig. $2 c$, mean daily incident PAR (see solid hedgerow) ranges from $2.5 \mathrm{~mol} / \mathrm{m}^{2}$ in winter to only $10.7 \mathrm{~mol} / \mathrm{m}^{2}$ in summer (solid hedgerow). Daily horizontally incident PAR at those times is 19.8 and $67.4 \mathrm{~mol} / \mathrm{m}^{2}$, respectively. The effect of porosity on interception is marked, however, and distinct in pattern compared with $\mathrm{N}-\mathrm{S}$ orchards. Radiation that penetrates sunlit sides of E-W hedgerows (Fig. 2b) passes to shaded sides (Fig. 2c), although with some loss by transmission that continues through to shaded alleys. The effect of porosity is greatest in winter when interception by shaded sides increases by $200 \%$ relative to the solid hedgerow (zero porosity).
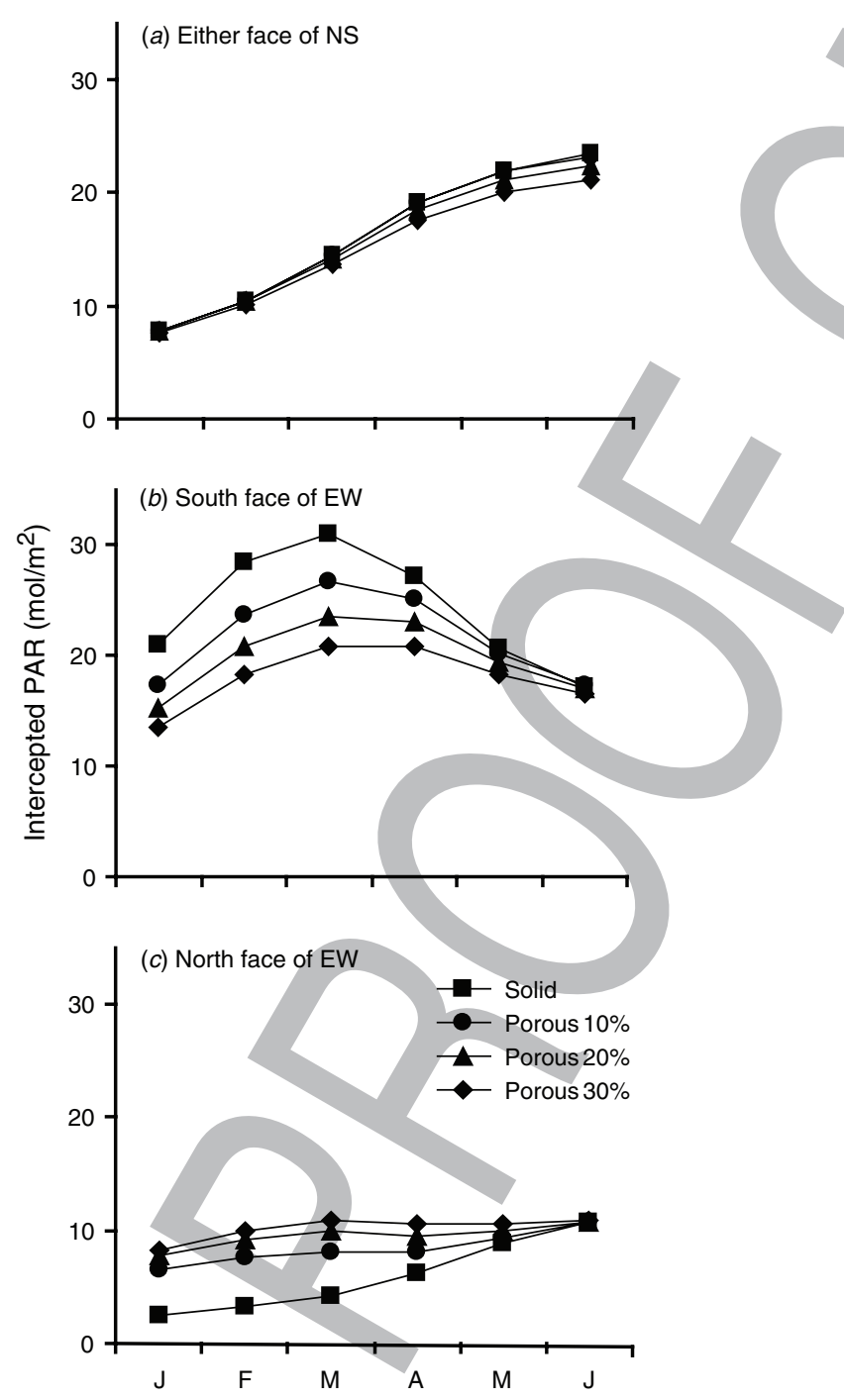

Fig. 2. Simulated daily interception of $P A R\left(\mathrm{~mol} / \mathrm{m}^{2}\right)$ by $\mathrm{N}-\mathrm{S}$ and $\mathrm{E}-\mathrm{W}$ hedgerow orchards by month of Northern-Hemisphere year in response to orientation and horizontal porosity: $(a)$ either face of the $\mathrm{N}-\mathrm{S}$ orchard, (b) sunlit face of the E-W orchard, (c) shaded face of the E-W orchard. The structures of the hedgerows are described in Appendix 1 (Orchard 10) and Appendix 2 (Orchard 12). More detail is available in Gómez-del-Campo et al. (2009), this issue.

\section{Yield profiles}

\section{North-south orchards in Spain and Australia}

Structures of these orchards are described in Appendix Table 1. All cultivars in Spain are cv. Arbequina and those in Australia are cvv. Barnea and Picual. Relationships of fruit size (g dry weight) and fruit oil content (\% dry weight) with PAR intercepted by component layers in October (Spain) or March (Australia) are presented in Fig. 3. The Spanish data also include some measurements made at the tops of canopies at full horizontal irradiance. October and March are chosen for analysis because they are central months, not only for fruit growth
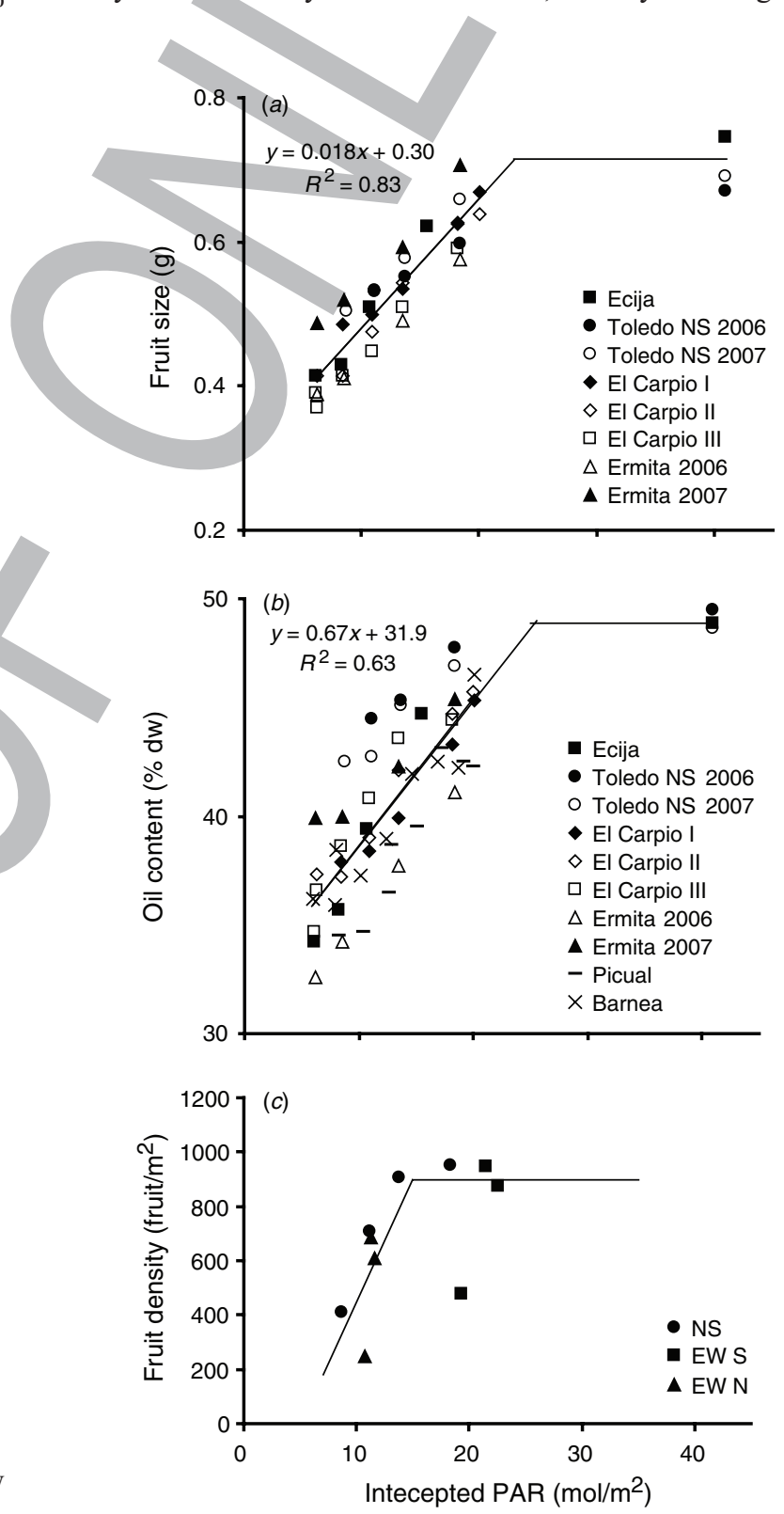

Fig. 3. Relationships between profiles of (a) fruit size for cv. Arbequina, (b) oil content for all cultivars, and (c) fruit density for N-S and E-W cv. Arbequina at Toledo in 2007 and daily intercepted PAR in October or March of various hedgerows in Spain and Australia. The structures of all orchards are described in Appendix 1. 
and oil production in the two hemispheres, but also for floral induction and differentiation (Connor and Fereres 2005). Relationships of intercepted horizontally incident radiation are similar for all months for $\mathrm{N}-\mathrm{S}$ orchards, but different for those oriented E-W (see Fig. 2).

Consistent relationships with intercepted daily PAR are evident across cv. Arbequina orchards for fruit size (Fig. 3a) and all orchards for oil content (Fig. 3b). Fruit size of cv. Arbequina increased from $0.40 \mathrm{~g}$ at PAR $6 \mathrm{~mol} / \mathrm{m}^{2}(15 \%$ of horizontally incident) to a maximum size of $0.72 \mathrm{~g}$ at PAR $23 \mathrm{~mol} / \mathrm{m}^{2}(56 \%$ of horizontally incident $)\left(R^{2}=0.83\right)$. Size responses for the larger fruited cvv. Barnea and Picual in Australian orchards do not reveal clear plateaux at high irradiance (not shown graphically but see Appendix Table 1). Those observations were not accompanied, however, by observations on fruit growing at full irradiance at the tops of hedgerows. Despite differences in fruit size among cultivars there is a common general relationship (Fig. 3b) between oil content and relative intercepted PAR. Oil content increased linearly from $36 \%$ at PAR $6 \mathrm{~mol} / \mathrm{m}^{2} \quad(15 \%$ horizontally incident) to a plateau value of $49 \%$ at PAR $25 \mathrm{~mol} / \mathrm{m}^{2}(60 \%$ horizontally incident) $\left(R^{2}=0.63\right)$.

There is no general relationship between fruit density and PAR intercepted by component layers of orchards, including for individual cultivars. Effect of interception is evident, however, in most orchards (Appendix 1 and 2) where maximum densities are observed in mid canopy, decreasing towards the base and top. Lower density towards the base is interpreted as a response to low irradiance and that at the top, where PAR is high, as less dense and more vegetative regrowth following pruning. An example is provided in Fig. $3 c$ for cv. Arbequina (Orchard 10, Appendix 1; Orchard 12, Appendix 2) in 2007. There, fruit density increases to 900 fruits $/ \mathrm{m}^{2}$ at around $15 \mathrm{~mol} / \mathrm{m}^{2}$ (37\% horizontal incident). That density is maintained except at the top of the canopy where density may fall to half. The data are, however, insufficient to define a (lower) threshold value of daily interception for fruit production. It appears, however, to be around $6 \mathrm{~mol} / \mathrm{m}^{2}(15 \%$ horizontally incident), the least illuminated locations from which fruit was collected.

\section{Comparison of $E-W$ and $N-S$ orchards of $c V$.}

\section{Arbequina in Spain}

Structures of these two orchards, presented in detail (including horizontal porosity) in Part I (Gómez-del-Campo et al. 2009), are summarised here in Appendix 1 (Orchards 9 and 10) and Appendix 2 (Orchards 11 and 12). These orchards are equally porous $(P<0.05)$, with mean horizontal porosities of 24 and $27 \%$, respectively. An important feature of their performance is high yield and considerable productivity of $\mathrm{N}$ sides of the $\mathrm{E}-\mathrm{W}$ orchard in both years. Analysis here seeks to relate components of yield to profiles of PAR intercepted by individual sides of hedgerows to those obtained in comparable N-S hedgerows. Relationships are again sought using PAR profiles during fruit filling in October when asymmetry in radiation intercepted by individual sides of $\mathrm{E}-\mathrm{W}$ hedgerows is large (Fig. $1 b, c)$.

General relationships between fruit size and oil content and intercepted PAR are evident in both orchards when analysed using mean horizontal porosity of $30 \%$. These data are presented in Fig. 4 together with comparable responses recorded in all other $\mathrm{N}-\mathrm{S}$ orchards of cv. Arbequina listed in Appendix 1. The fitted relationships are similar to those in Fig. $3 a$ and $b$. The noticeable feature is that both fruit size (Fig. 4a) and oil content (Fig. 4b) are generally large in all layers in E-W orchards compared with $\mathrm{N}-\mathrm{S}$ orchards. Whereas the relationship of fruit size to intercepted PAR on the $\mathrm{S}$ side was consistent with the plateau response observed previously at PAR $23 \mathrm{~mol} / \mathrm{m}^{2}$ (Fig. $3 a$ ), analysis reveals large fruit on the $\mathrm{N}$ face at lower PAR than in $\mathrm{N}-\mathrm{S}$ orchards. The relationship of oil content with intercepted PAR bears strong similarity to that of fruit size. Oil content on the $\mathrm{S}$ side was consistent, at the high interception $25 \mathrm{~mol} / \mathrm{m}^{2}(60 \%$ of horizontally incident), with the plateau at $60 \%$ intercepted PAR recorded in $\mathrm{N}-\mathrm{S}$ orchards (Fig. 3b). The $\mathrm{N}$ face, however, maintained high oil content at lower interception.

\section{Simulating effect of canopy structure on productivity in $\mathrm{CV}$. Arbequina at Toledo}

In 2007 this orchard (Appendix Table 1, Orchard 10) of N-S orientation and 4-m row spacing was $2.5 \mathrm{~m}$ tall and $1.0 \mathrm{~m}$ wide,
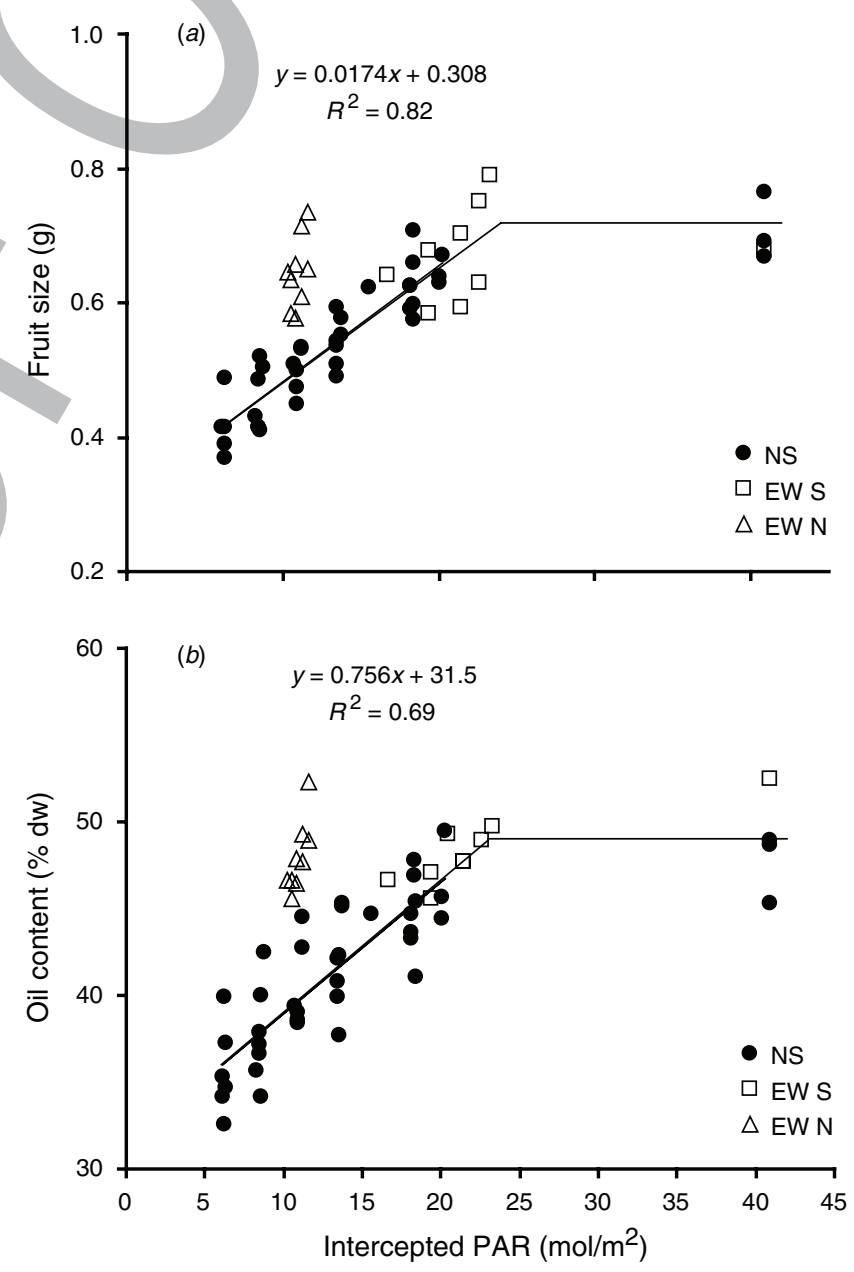

Fig. 4. Relationships between profiles of $(a)$ fruit size, and $(b)$ oil content and daily intercepted PAR in October for various $\mathrm{N}-\mathrm{S}$ and $\mathrm{E}-\mathrm{W}$ hedgerows of cv. Arbequina in Spain. The structures of the orchards are described in Appendix 1 (Orchards 9 and 10) and Appendix 2 (Orchards 11 and 12). The lines are fitted to $\mathrm{N}-\mathrm{S}$ data. 
with horizontal porosity of $24 \%$. The canopy is well illuminated (canopy depth/free alley ratio $=0.7$ ) so the following questions are to be considered. What is the effect of porosity on productivity? How tall and wide might the hedgerow grow before shading limits productivity? What would be the effect of changing porosity and orientation to E-W (in this case $20^{\circ} \mathrm{NE}-\mathrm{SW}$ ).

Effect of porosity on this orchard is presented in Table 1 . The initial effect of porosity $(10 \%)$ is to increase yield through greater fruit density, a result of transmission to the shaded lower parts of the opposite side of the hedgerow. At that low porosity there is no loss of productivity when sides are sunlit. As porosity increases further, however, yield decreases with relatively small effect, consistent with hedgerow geometry, until porosity exceeds $30 \%$. Interception is always symmetrical on either side before and after noon; porosity only determines what proportion of incident radiation is intercepted and what proportion passes completely through the hedgerow. That proportion is small because path lengths of the solar beam through the hedgerow are long during most of the day. In this case, simulated productivity for $20 \%$ porosity is $98 \%$, and for $30 \%$ (as measured for this orchard) is $92 \%$ of that for zero porosity.

Simulations of row height and width are presented in Table 2. Yield for the present structure is $346 \mathrm{~g} \mathrm{oil} / \mathrm{m}$ $(1730 \mathrm{~kg} / \mathrm{ha})$. Comparisons reveal that maintaining width at $1 \mathrm{~m}$ would increase yield with row height to a maximum value of $409 \mathrm{~g} / \mathrm{m}(2044 \mathrm{~kg} / \mathrm{ha})$ at $3.5 \mathrm{~m}$. Illumination of the lowest canopy layer would then be insufficient to increase productivity further. Yield gain at this optimum height for productivity would be $18 \%$ for a canopy depth/free alley ratio of 1.0. If, on the other hand, row height were not increased independently of canopy width, then greater canopy width of $1.5 \mathrm{~m}$ would, with low porosity, lower optimum height for

Table 2. Simulated yield for variations to hedgerow height and width of a N-S oriented cv. Arbequina orchard at Toledo, Spain (Orchard 10, Appendix 1)

The data are for either side with a yield total also presented for the hedgerow. Horizontal porosity for $1 \mathrm{~m}$ width is $30 \%$

\begin{tabular}{lrrr}
\hline Hedgerow height $(\mathrm{m}):$ & 2.5 & 3.5 & 2.5 \\
$\quad$ & 1.0 & 1.0 & 1.5 \\
\hline Hedgerow width $(\mathrm{m}):$ & 1683 & 1995 & 1585 \\
Fruit number (/m side) & 0.522 & 0.512 & 0.529 \\
Mean fruit size (g) & 40.3 & 40.0 & 40.6 \\
Mean oil content (\% DW) & 346 & 409 & 337 \\
Oil production (g/m side) & 1730 & 2044 & 1686 \\
Oil production (kg/ha) & & & \\
\hline
\end{tabular}

productivity to $2.5 \mathrm{~m}$, and without productivity gain for a canopy depth/free alley ratio of 0.8 .

E-W hedgerows have distinct and strong responses to porosity compared with $\mathrm{N}-\mathrm{S}$ hedgerows, as illustrated in simulations presented in Table 3 for yield of individual sides of Orchard 10 (Appendix 1), now oriented E-W. Illumination of shaded $\mathrm{N}$ faces depends upon radiation passing through from sunlit sides. In this case, with $10 \%$ porosity, the model predicts insufficient penetration to support productivity. Increasing porosity has a major effect on productivity and relative performance of sunlit and shaded sides because, as radiation becomes more evenly distributed between sides of hedgerows, total productivity also increases. Yield gain does not continue beyond 30\% porosity, however, because equality of performance by individual sides is then offset by lower total interception and hence productivity.

\section{Simulating effect of canopy structure on productivity in Cv. Barnea at Boundary Bend, Australia}

This orchard of 6-m row spacing is $5.5 \mathrm{~m}$ tall with hedgerows $2.5 \mathrm{~m}$ wide at the base and sloping $2.3^{\circ}$ from the vertical. The canopy depth/free alley ratio is 1.4 . Simulations are made for an estimated horizontal porosity of $5 \%$. Changes to hedgerow slope and width that can be accomplished by pruning effect illumination patterns on canopy walls and hence interception and productivity. Results of various simulations are presented in Table 4.

Simulations reveal that productivity of the current structure, yielding $605 \mathrm{~g} \mathrm{oil} / \mathrm{m}(2018 \mathrm{~kg} / \mathrm{ha})$, is limited by inadequate illumination at the canopy base. Height could be reduced by $0.25 \mathrm{~m}$ without loss of yield by eliminating that unproductive layer. The model suggests that yield could be increased (16\%) by increasing the slope to $5^{\circ}$, or further $(22 \%)$ by also reducing hedgerow width to $2 \mathrm{~m}$. Both options improve illumination at the base of the canopy. Analysis also reveals the importance of restricting further widening of hedgerows. Without modification to slope, an increase in width to $3.0 \mathrm{~m}$ would restrict illumination of lower hedgerow layers, as recorded in Table 4, by greater depth of unproductive canopy, and cause an estimated $10 \%$ loss of yield. Further, for that width-slope combination, hedgerow height could be reduced by $0.75 \mathrm{~m}$ without loss of productivity because it would eliminate the unproductive part at the canopy base.

\section{Discussion}

Measurements of PAR incident on faces of N-S and E-W hedgerows validated performance of a model used to estimate profiles of incident irradiance on walls of hedgerow canopies (Fig. 1). This is expected given equations that precisely describe

Table 3. Simulated yield for variations in horizontal porosity of a cv. Arbequina orchard oriented E-W at Toledo, Spain (Orchard 10, Appendix 1) The data are for individual sides (south, S; north, N) with a yield total also presented for the hedgerow

\begin{tabular}{|c|c|c|c|c|c|c|c|c|}
\hline \multirow{2}{*}{$\begin{array}{l}\text { Porosity (\%): } \\
\text { Hedgerow face: }\end{array}$} & \multicolumn{2}{|c|}{10} & \multicolumn{2}{|c|}{20} & \multicolumn{2}{|c|}{30} & \multicolumn{2}{|c|}{40} \\
\hline & $\mathrm{S}$ & $\mathrm{N}$ & $\mathrm{S}$ & $\mathrm{N}$ & $\mathrm{S}$ & $\mathrm{N}$ & $\mathrm{S}$ & $\mathrm{N}$ \\
\hline Fruit number (/m side) & 1733 & 0 & 1733 & 601 & 1733 & 1039 & 1733 & 1229 \\
\hline Mean fruit size $(\mathrm{g})$ & 0.700 & - & 0.699 & 0.412 & 0.675 & 0.435 & 0.612 & 0.445 \\
\hline Mean oil content $(\% \mathrm{DW})$ & 47.0 & - & 47.0 & 36.2 & 46.1 & 37.1 & 43.7 & 37.4 \\
\hline Oil production (g/m side) & 518 & - & 568 & 90 & 535 & 167 & 460 & 205 \\
\hline Oil production $(\mathrm{kg} / \mathrm{ha})$ & \multicolumn{2}{|c|}{1425} & \multicolumn{2}{|c|}{1644} & \multicolumn{2}{|c|}{1755} & \multicolumn{2}{|c|}{1633} \\
\hline
\end{tabular}


Table 4. Simulated yield for variations to hedgerow width and slope of a N-S oriented cv. Barnea orchard at Boundary Bend, Australia (Orchard 7, Appendix 1) with an estimated horizontal porosity for $2.5 \mathrm{~m}$ width of $5 \%$

The data are for either side with a total also presented for the hedgerow

\begin{tabular}{|c|c|c|c|c|c|c|c|c|c|}
\hline Canopy width (m): & & 2.0 & & & 2.5 & & & 3.0 & \\
\hline Canopy slope $\left({ }^{\circ}\right)$ : & 0 & 2.5 & 5.0 & 0 & 2.5 & 5.0 & 0 & 2.5 & 5.0 \\
\hline Fruit number (/m side) & 2750 & 2932 & 3010 & 2420 & 2668 & 2983 & 1992 & 2356 & 2793 \\
\hline Mean fruit size (g) & 0.531 & 0.560 & 0.574 & 0.524 & 0.542 & 0.542 & 0.524 & 0.543 & 0.542 \\
\hline Mean oil content (\% DW) & 40.2 & 41.4 & 42.0 & 39.9 & 40.7 & 41.6 & 40.0 & 40.7 & 40.7 \\
\hline Oil production ( $\mathrm{g} / \mathrm{m}$ side) & 608 & 696 & 736 & 523 & 605 & 703 & 430 & 535 & 639 \\
\hline Oil production (kg/ha) & 2026 & 2319 & 2452 & 1743 & 2018 & 2342 & 1433 & 1783 & 2129 \\
\hline Unproductive base (m) & - & - & - & 0.50 & 0.25 & - & 1.25 & 0.75 & - \\
\hline
\end{tabular}

diurnal irradiance and path of the sun. Extension of the model to estimate transmission of radiation through hedgerows follows the exponential extinction (EEP) scheme which, as explained in the Introduction, is well established in studies of hedgerows. Horizontal porosity was identified as a parameter of hedgerow structure that could be used to calculate transmission and hence interception by foliage within hedgerows generally. This parameter, the proportion (by layers) of horizontal gap, allows calculation of an exponential extinction coefficient from row width. That can then be applied to calculate transmission for all other solar path lengths as determined by solar altitude, azimuth relative to row direction, and row width. This is not the only definition of porosity in hedgerow studies. Oyarzun et al. (2007), for example, define porosity as the proportion of measured sunfleck in alley space between hedgerows at noon. They assume that this proportion increases/decreases linearly to zero from dawn and to dusk and use that relationship to calculate total interception by hedgerows.

Analysis of effect of porosity on interception by sides of hedgerows establishes important aspects of hedgerow performance (Fig. 2). First, it reveals that horizontal porosity, up to $30 \%$, has little effect on interception of PAR by $\mathrm{N}-\mathrm{S}$ hedgerows at temperate latitudes. Porosity does not change the symmetry of interception and there is little loss, i.e. negligible transmission through hedgerows, limited to $5 \%$ during summer. Radiation that passes through to shaded sides before noon is replaced by transmission after noon. Second, it reveals distinct behaviour of E-W hedgerows. For these, geometry of incidence of the solar beam provides greater PAR to sunlit faces (the solid hedgerow of Fig. $2 b$ ) than to N-S hedgerows in autumn, winter and spring. During that time, generally shorter path lengths also allow greater transmission through hedgerows, providing additional illumination to shaded sides. While these analyses demonstrate that porosity can be safely omitted from many analyses of $\mathrm{N}-\mathrm{S}$ hedgerows, they equally reveal that porosity plays a critical role in illumination of $\mathrm{E}-\mathrm{W}$ hedgerows and must, therefore, be included in analyses directed towards understanding productivity.

Analyses centred on relationships between yield parameters and intercepted PAR by individual sides of hedgerows (Fig. 3). These were made with clear-sky radiation for October (N Hemisphere) or March (S Hemisphere). These are central months, respectively, for fruit growth and oil production in the two hemispheres and also for floral induction and differentiation (Connor and Fereres 2005). Strong relationships were evident for fruit size and oil content in N-S orchards of varied structure from Spain and Australia. Variation among orchards was not large even though analyses were made against maximum irradiance on clear-sky days and did not account for differences in actual conditions between locations and years. The data suggest a value of daily intercepted radiation of $15 \mathrm{~mol} / \mathrm{m}^{2}$ (37\% horizontally incident) for full fruit set (Fig. 3c) while fruit size and oil content both increased to around $25 \mathrm{~mol} / \mathrm{m}^{2}$ (60\% of horizontally incident) (Fig. $3 a, b$ ). The value for fruit set is high by comparison with other tree crops (Heinicke 1966; Jackson 1970; Cain 1972). Cain (1972), for example, reported that $30 \%$ of horizontally incident radiation was required for full fruit set in apple at a higher latitude $\left(43^{\circ} \mathrm{N}\right)$ where radiation input is lower. High values for olive are consistent with high irradiance $\left(800-1000 \mu \mathrm{mol} / \mathrm{m}^{2} . \mathrm{s}\right.$, about $40 \%$ full sunlight intensity) required for saturation of photosynthesis of its sclerophyllous leaves (Connor and Fereres 2005). These observations clearly imply the need for widely spaced hedgerows (relative to height) for olive.

Simulations of productivity of selected hedgerow orchards confirm observations on yield parameters in $\mathrm{E}-\mathrm{W}$ and $\mathrm{N}-\mathrm{S}$ hedgerows. Porosity has little effect on yield of $\mathrm{N}-\mathrm{S}$ hedgerows (Table 1) but is critical to the performance of shaded sides of E-W hedgerows (Table 2) that depend upon transmission of radiation through from sunlit sides. As porosity increases, yield of shaded sides and entire orchards increases until interception greatly reduces overall productivity. This value was between 30 and $40 \%$ for the E-W orchard studied (Gómez-delCampo et al. 2009). In that experiment, the observed $\mathrm{S} / \mathrm{N}$ sideyield ratio of 1.6 recorded in 2007 was less than the value of 3.2 simulated for an orchard of equivalent structure and $30 \%$ porosity (Table 3). This emphasises the need for further work on the contribution of porosity to productivity of hedgerows and the possible importance of translocation of assimilates to areas that are poorly illuminated. This issue is not well understood. Proietti and Tombesi (1996) and Proietti et al. (2006) have, however, demonstrated that developing olive fruit can attract assimilates from nearby, better illuminated, foliage.

The value of the model was further demonstrated by practical examples with two existing commercial orchards. First, results suggest the extent to which yield of short $(2.5 \mathrm{~m})$, well spaced hedgerows $(4 \mathrm{~m})$ would be increased $(18 \%)$ by greater height (to $3.5 \mathrm{~m}$ ), and how optimum height (for maximum yield) would decrease to $2.5 \mathrm{~m}$ if hedgerow width were increased from 1.0 to $1.5 \mathrm{~m}$. Second, modifications were evaluated for a tall $(5.5 \mathrm{~m})$, widely spaced $(6 \mathrm{~m})$ orchard of hedgerow width $2.5 \mathrm{~m}$ and slope $2.5^{\circ}$ (Table 4 ). Analysis suggests that yield could be increased by 
$22 \%$ by reducing hedgerow width to $2.0 \mathrm{~m}$ and increasing slope to $5^{\circ}$. It also identified the importance of controlling hedgerow width. Wider hedgerows $(3 \mathrm{~m})$, with existing height and row spacing, would reduce productivity $(10 \%)$ by increasing shading in lower layers of the hedgerow.

This study has made considerable progress both in defining yield responses in $\mathrm{N}-\mathrm{S}$ hedgerow orchards and in seeking explanations of comparative performance of $\mathrm{E}-\mathrm{W}$ hedgerows. In this analysis of observed responses of yield components, the application of a model of transmission and interception has proved valuable. It is, however, important not to generalise from limited data collected in this study. The challenge remains to move beyond the conflicting results reported by Jackson (1980) with regard to advantages and disadvantages of alternative orchard structures in various locations. Quantitative relationships of yield component response to radiation interception provide a valuable approach that requires further data and analysis. Here, useful explanations of fruit size and oil content in a range of orchards were not equally matched by explanations of fruit density. A methodology has been developed to study light relations in E-W orchards but more data are required, in particular from less well illuminated orchards of any orientation, to define lower limits of response to radiation.

\section{Acknowledgments}

We express our gratitude to Prof. Diego Barranco from Universidad de Córdoba for use of oil measurement equipment, and Dr Leandro Ravetti of Modern Olives, Lara, Victoria, Australia, for the measurements made on orchards of cvv. Picual and Barnea at Boundary Bend, Victoria, Australia. We gratefully acknowledge Jacinto Cabetas from El Carpio de Tajo and Antonio Capitán from Écija for access to olive orchards where this research was conducted.

\section{References}

Annandale JG, Jovanovic NZ, Campbell GS, Du Sautoy N, Lobit P (2004) Two-dimensional solar radiation interception model for hedgerow fruit trees. Agricultural and Forest Meteorology 121, 207-225. doi: 10.1016/ j.agrformet.2003.08.004

Cain JC (1972) Hedgerow orchard design for most efficient interception of solar radiation. Effects of tree size, shape, spacing, and row direction. Search 2, 1-14.

Cohen S, Fuchs M (1987) The distribution of leaf area, radiation, photosynthesis and transpiration in a Shamouti orange hedgerow orchard. Part I. Leaf area and radiation. Agricultural and Forest Meteorology 40, 123-144. doi: 10.1016/0168-1923(87)90002-5

Cohen S, Fuchs M, Moroshet S, Cohen Y (1987) The distribution of leaf area, radiation, photosynthesis and transpiration in a Shamouti orange hedgerow orchard. Part II. Photosynthesis, transpiration, and the effect of row shape and direction. Agricultural and Forest Meteorology 40, 145-162. doi: 10.1016/0168-1923(87)90003-7
Connor DJ (2006) Towards optimal designs for hedgerow olive orchards. Australian Journal of Agricultural Research 57, 1067-1072. doi: 10.1071/AR05448

Connor DJ, Fereres E (2005) The physiology of adaptation and yield expression in olive. Horticultural Reviews 34, 155-229.

Friday JB, Fownes JH (2001) A simulation model for hedgerow light interception and growth. Agricultural and Forest Meteorology 108, 29-43. doi: 10.1016/S0168-1923(01)00220-9

Gijzen H, Goudriaan J (1989) A flexible and explanatory model of light distribution and photosynthesis in row crops. Agricultural and Forest Meteorology 48, 1-20. doi: 10.1016/0168-1923(89)90004-X

Gómez-del-Campo M, Centeno A, Connor DJ (2009) Yield determination in olive hedgerow orchards. I. Yield and profiles of yield components in north-south and east-west oriented hedgerows. Crop and Pasture Science 60, xxx-yyy.

Heinicke DR (1966) Characteristics of McIntosh and Red Delicious apples as influenced by exposure to sunlight during the growing season. Proceedings of the American Society for Horticultural Science 89, 10-13.

Jackson JE (1970) Aspects of light climate within apple orchards. Journal of Applied Ecology 7, 207-216. doi: 10.2307/2401373

Jackson JE (1980) Light interception and utilization by orchard systems. Horticultural Reviews 2, 208-267.

Jackson JE, Palmer JW (1972) Interception of light by model hedgerow orchards in relation to latitude, time of year and hedgerow configuration and orientation. Journal of Applied Ecology 9, 341-357. doi: 10.2307/ 2402436

Mariscal MJ, Orgaz F, Villalobos FJ (2000) Modelling and measurement of radiation interception by olive canopies. Agricultural and Forest Meteorology 100, 183-197. doi: 10.1016/S0168-1923(99)00137-9

Olesen T, Morris S, McFadyen L (2007) Modelling the interception of photosynthetically active radiation by evergreen subtropical hedgerows. Australian Journal of Agricultural Research 58, 215-223. doi: 10.1071/AR06110

Oyarzun RA, Stöckle CO, Whiting MD (2007) A simple approach to modeling radiation interception by fruit-tree orchards. Agricultural and Forest Meteorology 142, 12-24. doi: 10.1016/j.agrformet.2006.10.004

Palmer JW, Jackson JE (1977) Seasonal light interception and canopy development in hedgerow and bed system apple orchards. Journal of Applied Ecology 14, 539-549. doi: 10.2307/2402566

Proietti P, Nasini L, Famiani F (2006) Effect of different leaf-to-fruit ratios on photosynthesis and fruit growth in olive (Olea europaea L.). Photosynthetica 44, 275-285. doi: 10.1007/s11099-006-0019-4

Proietti P, Tombesi A (1996) Translocation of assimilates and source-sink influences on productive characteristics of the olive tree. Advances in Horticultural Science 10, 11-14.

Smart RE (1982) Vine manipulation to improve wine grape quality. In 'Proceedings of the International Symposium of Grapes and Wine'. California, 1980. pp. 362-375.

Manuscript received 1 August 2008, accepted 6 February 2009 
Appendix 1. Structure and yield profiles (means of two faces) of NS orchards in Spain and Australia Additional data for Orchards 9 and 10 are available in Gómez-del-Campo et al. (2009, this issue)

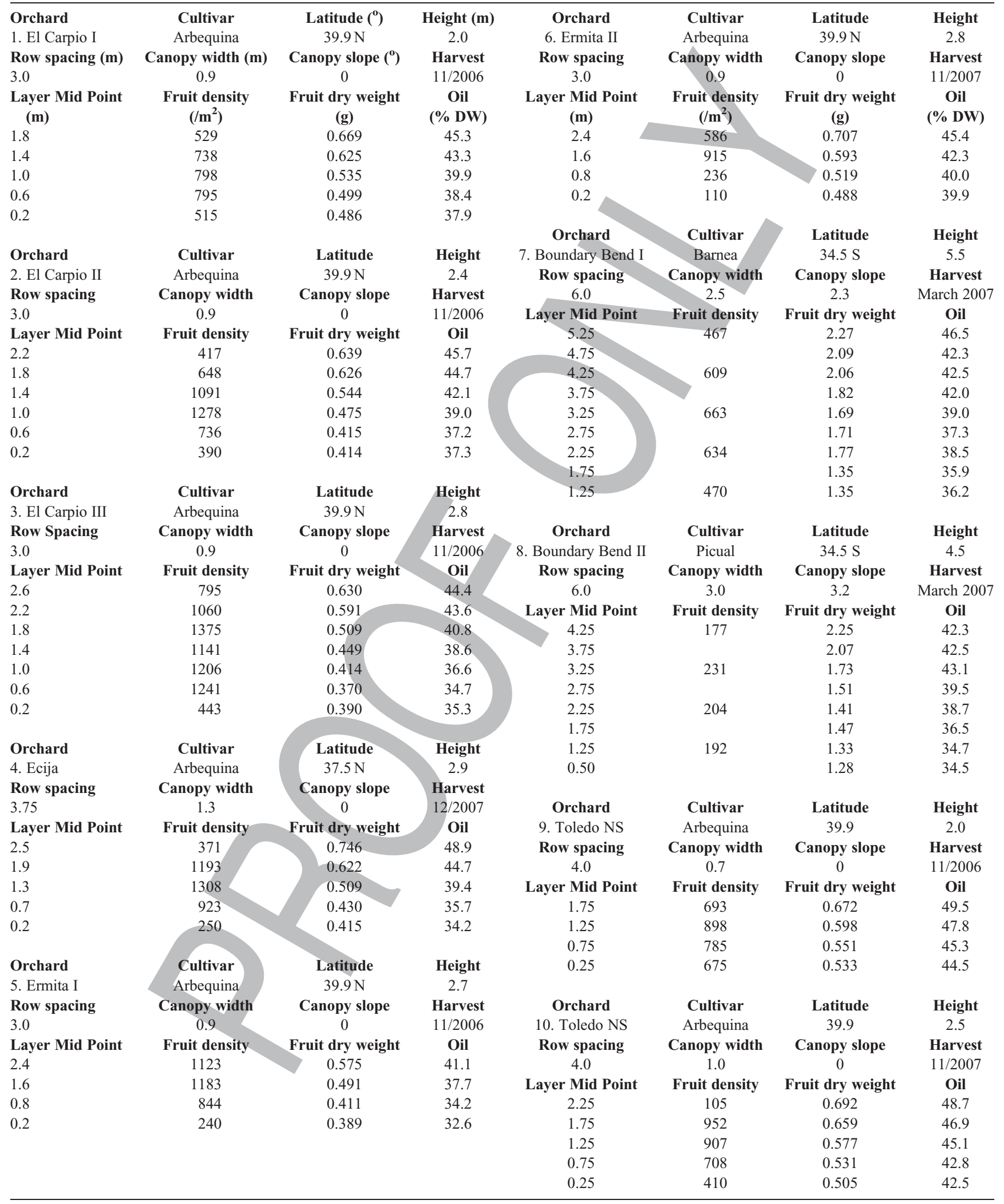


Appendix 2. Structure and yield profiles of $E-W$ orchards in Spain

Additional detail is available in Gómez-del-Campo et al. (2009, this issue)

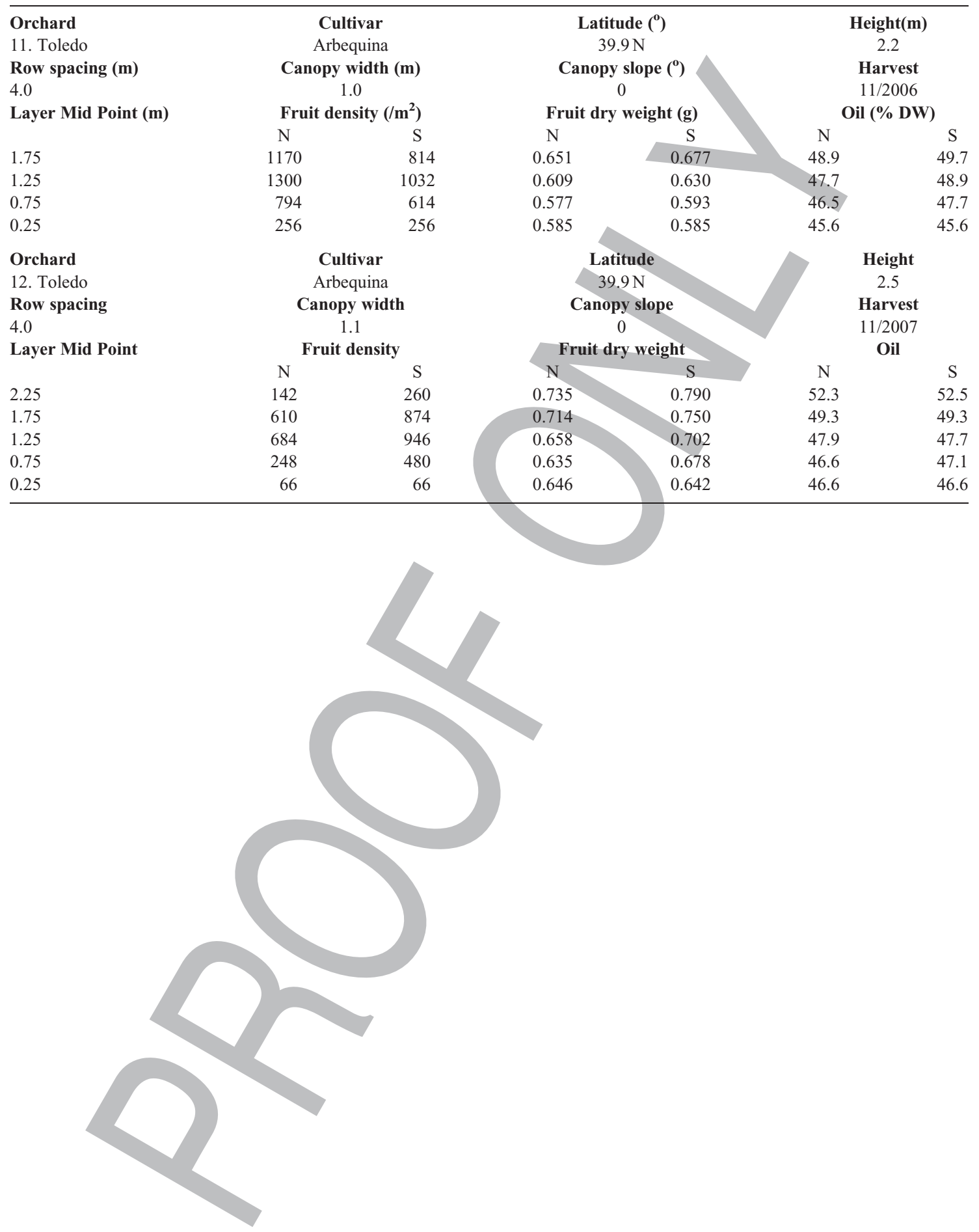

